\title{
O REGIME INTERNACIONAL DE EDUCAÇÃO: PRINCÍPIOS E NORMAS DA EDUCAÇÃO PROFISSIONAL
}

THE INTERNATIONAL EDUCATION REGIME: PRINCIPLES AND NORMS OF VOCATIONAL EDUCATION

\section{EL RÉGIMEN INTERNACIONAL DE EDUCACIÓN: PRINCIPIOS Y NORMAS DE LA FORMACIÓN PROFESIONAL}

\section{Jan Peter Ganter de Otero*}

* Doutorando em Educação Comparada pela Universidade de Osnabrück, Alemanha. Münster, North Rhine-Westphalia, Alemanha. E-mail: janotero@gmail.com

Recebido para publicação: em 12.4.2018

Aprovado em: 12.3.2019

\section{Resumo}

Este trabalho analisa o conteúdo do consenso internacional acerca da Educação Profissional, apresentando esta modalidade de educação como importante na agenda de debates sobre o desenvolvimento socioeconômico das nações. Para isso, busca identificar os princípios e as normas da educação profissional existentes no Regime Internacional de Educação, com base na análise de conteúdo das recomendações da Organização das Nações Unidas para a Educação, a Ciência e a Cultura (Unesco).

Palavras-chave: Educação Profissional. Regime Internacional de Educação. Educação Técnica e Profissional.

\begin{abstract}
This paper analyzes the content of the international consensus on Vocational Education, presenting this type of education as important in the agenda of debates on the socioeconomic development of nations. To this end, it seeks to identify the principles and norms of vocational education existing in the International Education Regime, based on the content analysis of the recommendations of the United Nations Educational, Scientific and Cultural Organization (Unesco).
\end{abstract}

Keywords: Vocational Education. International Education Regime. Technical and Vocational Education.

\section{Resumen}

Este trabajo analiza el contenido del consenso internacional sobre la Formación Profesional, presentando esta modalidad de educación como importante en la agenda de 
debates sobre el desarrollo socioeconómico de las naciones. Para ello, se busca identificar los principios y las normas de la formación profesional existentes en el Régimen Internacional de Educación, con base en el análisis de contenido de las recomendaciones de la Organización de las Naciones Unidas para la Educación, la Ciencia y la Cultura (Unesco).

Palabras clave: Formación Profesional. Régimen Internacional de Educación. Educación Técnica y Profesional.

\section{Introdução}

No cenário internacional, a partir do fim da década de 1980, a educação profissional ganhou espaço e importância, sendo objeto de diversos debates em congressos e conferências. Em 1987, em Berlim, ocorreu o primeiro congresso internacional em Technical and Vocational Education (TVET) - nomenclatura que designa a modalidade de educação profissional no contexto internacional. Como resultado do congresso, realizado em 1989, em Paris, a Organização das Nações Unidas para a Educação, a Ciência e a Cultura (Unesco), organizadora principal do congresso, aprovou a primeira convenção internacional estritamente dedicada ao tema da educação profissional (UNESCO, 1989).

Dez anos depois, em 1999, foi realizado o $2^{\circ}$ Congresso Internacional de TVET, em Seul. Os consensos produzidos pelo congresso foram sistematizados no documento Revised Recommendation concerning Technical and Vocational Education, publicado pela Unesco em 2001. Esse texto, considerado um dos principais documentos normativos da educação profissional e tecnológica no cenário internacional, tem como objetivo guiar os países membros no sentido de reformar os sistemas de TVET, adequando-os às demandas do mundo contemporâneo e do mercado de trabalho.

A análise de conteúdo de documentos no molde proposto por Bardin (2009) é a base metodológica utilizada nesta pesquisa. A seguir, apresenta-se o conceito de regime internacional elaborado por Krasner (1983), bem como as três correntes clássicas de análise acerca do conceito. A parte subsequente é dedicada aos princípios e às normas da educação profissional existentes no Regime Internacional de Educação a partir da análise de conteúdo do documento.

Desse modo, o objetivo deste trabalho é analisar o conteúdo do consenso internacional acerca da Educação Profissional, apresentando essa modalidade de educação como assunto de grande importância na agenda de debates acerca do desenvolvimento socioeconômico das nações. Para isso, faz uso da teoria dos "Regimes Internacionais" (KRASNER, 1983), buscando identificar os princípios e as normas da educação profissional existentes no Regime Internacional de Educação, a partir da análise de conteúdo do documento Revised Recommendation concerning Technical and Vocational Education (UNESCO, 2001). 


\section{0 conceito de regime internacional}

A teoria dos

regimes deve

ser vista no

contexto das

discussões sobre

governança
Segundo Amaral (2010), atualmente, nas ciências sociais, o termo "regime" possui diferentes compreensões, no entanto, todas se aproximam da ideia de um conjunto de regras governantes e princípios que controlam um campo particular de ação. Assim, para o autor, regimes são estruturas de regulação mais ou menos independentes de seus participantes, com formas dinâmicas de organização social que se baseiam tanto em elementos formais como informais e permeados por uma rede complexa de agentes interessados. Amaral (2010) defende que a teoria dos regimes deve ser vista no contexto das discussões sobre governança, uma vez que ambos os conceitos compartilham seu objeto de pesquisa, ou seja, "ambos focam as diferentes concepções de como os processos de regulação sociopolítica são coordenados entre os diversos agentes, públicos e privados" (AMARAL, 2010, p. 42). 0 autor afirma que:

Os conceitos de governança e regime internacional se referem a princípios e regras de decisão coletiva em contextos onde há uma pluralidade de agentes ou constelação de agentes (estados, organismos internacionais etc.) e onde não há um Sistema estritamente formal de controle capaz de ditar as regras do jogo entre eles, como é o caso da dimensão internacional das políticas públicas de educação (AMARAL, 2010, p. 42).

Stephen Krasner (1983) elaborou a definição clássica de regimes internacionais largamente utilizada ainda hoje: "Conjunto de princípios implícitos ou explícitos, normas, regras e procedimentos de tomada de decisões em torno dos quais cada ator converge suas expectativas em uma dada área das relações internacionais" (KRASNER, 1983, p. 2). Utiliza essa definição como ponto de partida para as discussões em torno do conceito de regime internacional. O autor apresenta três correntes de análise acerca do conceito presente no livro: (1) as orientações estruturais convencionais que desvalorizam os regimes como sendo ineficazes ou inexistentes; (2) as orientações grocianas, que veem os regimes como elementos inerentes ao Sistema internacional; e (3) a perspectiva estruturalista modificada, que admite a existência de regimes em certas condições restritas, podendo ser considerada um posicionamento de conciliação entre a perspectiva realista e a institucionalista das relações internacionais. O autor aponta os artigos de Young (1983) e Puchala e Hopkins (1983) como exemplos da orientação grociana. O texto de Strange (1982) é representante da visão estruturalista tradicional. No entanto, a maioria dos textos do livro pode ser classificada como estruturalista modificada, uma vez que aceitam os pressupostos analíticos básicos das abordagens estruturalistas realistas, mas sustentam que, sob certas condições, os regimes internacionais podem ter um impacto significativo, mesmo em um mundo anárquico. Para essa última corrente, o autor identifica, principalmente, o trabalho de Keohane (1983) como grande contribuição. 
Na tradição estruturalista, o trabalho de Strange (1982), é considerado uma importante síntese da análise crítica do conceito de regime internacional. Strange promove uma série de críticas ao campo dos regimes internacionais. Argumenta que o conceito é pernicioso porque ofusca e obscurece as relações entre poder e interesses, que são não apenas as mais importantes, mas, sobretudo, as causas fundamentais do comportamento dos estados no sistema internacional. A autora analisa a origem dos estudos do campo, situando-a nos Estados Unidos dos anos 1970. Segundo Strange, o estudo dos regimes internacionais é um interesse norte-americano com objetivo de se manter hegemônico no sistema. Diante dos problemas enfrentados pelos EUA na década em que surgem os primeiros trabalhos sobre o termo, seria um mecanismo encontrado para minimizar as dificuldades nacionais e internacionais do país. Então, é importante notar que Strange parte da ideia de que os EUA, como a maior potência mundial, teriam condições de condicionar a ação dos atores internacionais de acordo com seus interesses.

Do outro lado da discussão, a tradição grociana, a qual vê regimes como fenômenos disseminados em todos os sistemas políticos, com fundamental impacto nas ações dos estados-nações. Young (1983) discorda da análise de Susan Strange, que vê os regimes internacionais como modismo acadêmico imparcial. E defende que os regimes internacionais são arranjos institucionais que ajudam a explicar e até mesmo a determinar o comportamento dos atores internacionais. Nessa visão, Puchala e Hopkins afirmam que:

Regimes existem em todas as áreas temáticas, mesmo naquelas em que há grande rivalidade de poder, vistas tradicionalmente como exemplos nítidos de anarquia. Os estadistas quase sempre se sentem restringidos por princípios, normas e regras que prescrevem e proscrevem diferentes comportamentos (PUCHALA; HOPKINS, 1983, p. 270).

Para os autores dessa corrente, o papel do desenvolvimento de uma cultura mundial é fundamental para se atingir uma teoria analítica das relações internacionais mais adequada, pois, da forma como argumentam, o sistema internacional não deve ser compreendido somente como composto por estados soberanos que buscam sua sobrevivência como único objetivo. Young argumenta que a relação entre os agentes no cenário internacional, inevitavelmente, gera expectativas convergentes, gerando, assim, normas reconhecidas em um regime internacional, o qual, por sua vez, acentua os comportamentos dos agentes. Essa relação dialética é compreendida como inerente à vida política dos estados e, por isso, esses autores defendem a existência dos regimes em todos os campos de atuação política.

Finalmente, como conciliação das duas vertentes apresentadas, a visão de Robert Keohane (1983) surge entre as mais importantes da corrente chamada aqui de "estruturalismo modificado". Apesar de partir da visão realista estruturalista convencional, ou seja, um mundo de estados soberanos buscando maximizar seus interesses e poderes, para esse autor, o conceito de "regime internacional" não deve 
ser negado pelos autores estruturalistas. Segundo sua visão, os regimes surgem de acordos voluntários entre atores juridicamente iguais como grupos de arranjos de governança que incluem redes de regras, normas e procedimentos responsáveis por regulamentarem o comportamento de seus membros. Assim, em um mundo de estados soberanos, a função básica dos regimes é coordenar o comportamento dos estados em áreas particulares de interesse em que a cooperação internacional contribui para que cada membro possa atingir os resultados desejados.

Neste momento, para os objetivos deste artigo, é importante sinalizar dois apontamentos, a saber: (1) fundamentar princípios, normas, regras e procedimentos de tomada de decisão; e (2) diferenciar os termos "regime internacional" e "organismos internacionais". Recuperando a definição de Krasner, o autor explica que:

Princípios são crenças em fatos, causas e questões morais. As normas são padrões de comportamento definidos em termos de direitos e obrigações. Regras são ordens e proibições para ação. Procedimento de tomada de decisões são práticas prevalecentes para fazer ou implementar escolha coletiva (KRASNER, 1983, p. 2-3).

Ainda segundo Krasner (1983), é necessário realizar uma diferenciação entre princípios e normas, de um lado; e regras e procedimentos, de outro. Segundo o autor, principíos e normas fornecem as características básicas definidoras de um regime. Quaisquer alterações realizadas nessa base primordial dos regimes devem ser compreendidas como mudança de regime. No entanto, diferentes regras e procedimentos de tomada de decisão podem ser compatíveis com os mesmos princípios e normas, de forma que qualquer mudança nesses elementos de um regime deve ser interpretada como mudança interna no regime. Segundo Krasner (1983), os argumentos políticos mais fundamentais estão mais relacionados a normas e princípios do que a regras e procedimentos. É importante também ressaltar que, para Krasner (1983), se os princípios, as normas, as regras e os procedimentos de tomada de decisão de um regime tornam-se menos coerentes entre si, então esse regime se enfraqueceu. A solidez de um regime se dá exatamente pela manutenção de seus princípios e normas, e pela coerência destes com as regras e os procedimentos adotados.

Ao propor a ideia de um regime internacional de educação, Amaral (2010) identifica alguns dos princípios e normas relativos à educação no cenário internacional, mas, principalmente, apresenta suas suposições acerca do tipo de regime, sua formação e seus membros. Para o autor, princípios servem para interpretar a realidade na qual os problemas e conflitos serão resolvidos cooperativamente por um regime. Os princípios incorporam conceitos básicos, e, no caso, do regime internacional de educação, Amaral sinaliza, de antemão, pelo menos dois princípios fundamentais: o primeiro seria aquele derivado da concepção de ser humano do pensamento iluminista, que estende a todos a capacidade de aprender, necessitando de educação para seu desenvolvimento individual. O segundo, tomado em consequência do primeiro, destaca 
os retornos socioeconômicos que a educação pode beneficiar, especialmente em relação à inclusão social e ao crescimento econômico. Quanto às normas, entendidas como direcionamentos instrutivos gerais, o autor ressalta a função dos direitos humanos, especialmente, o direito à educação como a norma mais reconhecida nas sociedades modernas - e a norma da educação compulsória.

caso do regime internacional de educação pode ser considerado um processo de autogeração
Ao sinalizar que tais princípios e normais foram de suma importância para a emergência do regime internacional de educação, mais precisamente a partir da segunda metade do século 20, Amaral (2010) se aproxima da concepção de regime internacional apresentada pelos autores grocianos, uma vez que compreendiam a possibilidade de um regime internacional se formar a partir da construção de ideais basilares, como estes aqui descritos. Segundo o autor, o caso do regime internacional de educação pode ser considerado um processo de autogeração, a partir da convergência de expectativas dos participantes, não sendo, portanto, algo negociado ou imposto. É nesse sentido que o autor destaca os entendimentos mútuos que vêm sendo construídos internacionalmente sobre "o que é" ou "o que deve ser" a educação, presentes em diversas iniciativas comparativas, como os exames e programas de avaliação internacionais, ou ainda, conferências e congressos mundiais em educação.

O segundo apontamento é a diferenciação entre os termos "regime internacional" e "organismos internacionais". Amaral (2010) afirma que, apesar de grande parte dos estudos terem como foco a ação dos estados nos regimes, é fundamental destacar que, cada vez mais, a diversidade e complexidade de atores no cenário internacional se intensificam, especialmente com a entrada das organizações não governamentais (ONGs). Essa afirmação tem grande importância para este trabalho, pois sinaliza que não se devem confundir os regimes internacionais com os organismos internacionais, como aconteceria, por exemplo, no caso deste trabalho, se o objetivo fosse interpretar a Unesco em si como o regime internacional de educação. Apesar de encontrar em um documento da Unesco a possibilidade de reconhecer princípios e normas, isso não significa que a organização internacional representa todo o regime. Portanto, o objeto de estudo não é a Unesco e, sim, o regime internacional de educação, seus princípios e normas relativos à TVET.

\section{Princípios e normas da educação profissional}

Nesta seção, o objetivo é identificar os princípios e as normas existentes no Regime Internacional de Educação com foco na temática da TVET, a partir da análise de conteúdo do documento Revised Recommendation concerning Technical and Vocational Education (UNESCO, 2001), tendo como metodologia a análise de conteúdos no molde proposto por Bardin (2009) no livro L'analyse de contenu, de 1977. Segundo a autora, a análise de conteúdo é um conjunto de técnicas de análise de comunicações, por meio de procedimentos sistemáticos que permitem reagrupar os conteúdos 
emitidos pelas mensagens, a partir de novas categorias de análise, que devem surgir do cruzamento dos referencias teóricos com os dados colhidos. A análise de conteúdos de Bardin pressupõe a elaboração de três etapas distintas, que podem se desenvolver de forma concomitante em certos momentos: a pré-análise, a exploração do material e o tratamento dos resultados. Na pré-análise, cabe ao pesquisador realizar a organização do material, defınindo o corpus da pesquisa, ou seja, quais os documentos principais que devem ser analisados, bem como os documentos secundários que devem servir de apoio.

A seleção do documento publicado pela Unesco Revised Recommendation concerning Technical and Vocational Education, para os fins deste trabalho, justifica-se por alguns argumentos. Primeiramente, trata-se de um documento elaborado com o intuito de revisar as recomendações da comunidade internacional quanto ao funcionamento dos sistemas nacionais de educação profissional, e que fora diretamente construído a partir das discussões e dos consensos elaborados a partir do $2^{\circ}$ Congresso Internacional de TVET, realizado em Seul, em 1999. Entendido, portanto, que se trata de produto de um "procedimento de tomada de decisão", é possível afirmar que representa o que há de consenso quanto à Educação Profissional no Regime Internacional de Educação. O documento tem como objetivo guiar uma nova orientação sobre a TVET na construção dos sistemas nacionais de educação, de acordo com as demandas do século 21 e com o objetivo de contribuir para o fortalecimento de uma cultura de paz, desenvolvimento sustentável, coesão social e cidadania mundial.

Porém, antes de entrar precisamente na análise dos dados do documento, é importante sinalizar que esse se enquadra em uma tradição da Unesco de produzir recomendações acerca de temas importantes, por meio de um processo de discussão internacional, na forma de congressos e diversos eventos preparatórios. No caso da TVET, a primeira versão do documento de recomendações foi publicada pela Unesco, no ano de 1962, e revisada nos anos de 1974 e 2001.

Uma vez que a versão do documento aqui analisado advém das contribuições do $2^{\circ}$ Congresso Internacional, de Seul, de 1999, é importante destacar alguns pontos relativos ao contexto das discussões. O congresso, que teve como mote Lifelong learning and training: a bridge to the future [Aprendizado ao longo da vida: uma ponte para o futuro], objetivou construir novos padrões internacionais (standard settings) diante da percepção do novo contexto socioeconômico dos últimos anos do século 20. O contexto das discussões do congresso se apresenta no primeiro artigo do documento, que remete à criação de uma sociedade da informação global gerada pelas tecnologias da informação e comunicação, que modificam o aprendizado e o trabalho, ao passo que cresce a consciência de que o desenvolvimento sócio-econômico é insustentável devido ao seu grau nocivo ao meio ambiente (INTERNATIONAL CONGRESS ON TECHNICAL AND VOCATIONAL EDUCATION, 1999, art.1). 
O desenvolvimento científico e tecnológico, as mudanças nas configurações do trabalho e o crescimento da consciência do impacto do desenvolvimento socioeconômico nas condições de vida e do ambiente são notados como os principais elementos que levam à discussão de um novo paradigma de desenvolvimento. Diante disso, o documento defende que a TVET deve assumir uma nova perspectiva de atuação. Como demonstra trecho do décimo artigo, que salienta a necessidade de que a aprendizagem, ao longo da vida, deve se adequar às necessidades de estudantes, trabalhadores e empregadores com treinamentos que considerem 0 uso criterioso dos recursos naturais (INTERNATIONAL CONGRESS ON TECHNICAL AND VOCATIONAL EDUCATION, 1999, art. 10).

Perante esse desafio, o evento contou com a participação de mais de

A TVET deve assumir uma nova perspectiva de atuação
700 pessoas de 130 países, incluindo 40 ministros da Educação, três agências da Organização das Nações Unidas (ONU) e 29 organizações intergovernamentais e não governamentais para discutir como a TVET deveria se adaptar tendo em vista os desafios do mundo do trabalho no século 21 (UNESCO, 1999). As discussões do congresso contaram com seis temas fundamentais: (1) As novas exigências do século 21: desafios para a educação técnica e profissional; (2) Melhorar os sistemas de ensino ou a formação ao longo da vida; (3) Inovando a educação e o processo de formação; (4) TVET para todos; (5) Mudar papéis do governo e outras partes interessadas na TVET; (6) Reforçar a cooperação internacional na TVET (UNESCO, 1999, p.2).

Segundo o documento, destacam-se entre os resultados dos debates do congresso: (I) O reconhecimento da importância da TVET como instrumento de coesão social e empoderamento de jovens e adultos; (II) a compreensão da necessidade de articulação com a TVET não formal; (III) a consideração da TVET de acordo com a expressão "education for all through-out life"; [educação para todos por toda a vida]; (IV) o reconhecimento da necessidade de favorecer a entrada de grupos de minorias, etnias, comunidades tradicionais, refugiados e ex-combatentes de guerra nos programas e cursos de TVET; (V) os estímulos à superação de estereótipos de gênero na TVET; $(\mathrm{VI})$ a defesa da adoção de programas e cursos flexíveis, a partir do uso de tecnologias de comunicação e informação, especialmente para o atendimento a áreas remotas; (VII) o reconhecimento da necessidade de estimular a adoção de modelos de TVET fundamentados na ideia de desenvolvimento sustentável.

Ao término do congresso de 1999, coube à Unesco construir uma nova versão do documento de recomendações, a partir dos resultados atingidos. Aprovado em 2 de novembro de 2001, em plenária da conferência geral da Unesco, o documento normativo Revised Recommendation concerning Technical and Vocational Education resume em exatos 100 artigos $^{1}$ os consensos produzidos durante as discussões relativas ao congresso, tratando de um amplo universo de temas, como a concepção e os objetivos de TVET, a fundamentação do termo, além de orientações acerca da elaboração de políticas públicas, currículo, orientação profissional, condições de trabalho e, especialmente, a relação da TVET com a educação básica dentro da 
perspectiva da formação continuada. O documento apresenta uma autoconcepção em seu $4^{\circ}$ artigo, ressaltando se as recomendações devem ser aplicadas por cada país conforme suas necessidades socioeconômicas, com vistas também a melhorar o ensino técnico e profissional (UNESCO, 2001, art. 4).

Ao estabelecer princípios, metas e linhas de orientação, o documento busca definir a educação técnica e profissional como um processo que envolve, além da educação geral, o estudo de tecnologias e ciências concernentes, assim como a aquisição de habilidades práticas e conhecimentos relacionados com ocupações em diversos setores econômicos e sociais. O documento salienta, ainda, que a educação profissional é um método para facilitar a redução da pobreza (UNESCO, 2001, art. 2).

A análise do material foi feita por intermédio de uma descrição analítica capaz de construir um quadro de referências a partir das categorias de "princípios" - crenças em fatos, causas e questões morais; e "normas" - padrões de comportamento definidos em termos de direitos e obrigações do Regime Internacional de Educação. A partir do reconhecimento dos elementos textuais, segundo as definições mencionadas, é possível constatar pelo menos quatro princípios e cinco normas, sobre os quais todo o consenso internacional acerca da Educação Profissional se constrói:

\subsection{Princípio da contribuição da educação profissional para o desenvolvimento individual}

0 princípio da contribuição para o indivíduo é a origem da defesa da implantação de sistemas de TVET em todas as nações
Esse princípio se relaciona diretamente com aquele apresentado por Amaral (2010) acerca do regime internacional de educação de uma forma geral: a crença no fato de que todo e qualquer ser humano é capaz de aprender e de produzir conhecimento por meio de suas aptidões mentais e físicas. Esse princípio, originário no pensamento iluminista, permanece norteando todo o entendimento acerca da condição humana nos documentos internacionais. A partir dessa compreensão de ser humano, o documento apresenta a TVET como forma de educação capaz de contribuir fortemente para o desenvolvimento do potencial de todos os indivíduos. O documento destaca que a educação profissional deve levar as pessoas a terem uma visão crítica sobre as decorrências políticas, sociais e ambientais das mudanças científicas e tecnológicas contemporâneas (UNESCO, 2001, art. 5b).

As contribuições da TVET para os indivíduos aparecem ainda mais claras no artigo $8^{\circ}$, o qual destaca, ainda, sua função de desenvolver também as capacidades para tomada de decisões no trabalho em equipe e na liderança comunitária como um todo (UNESCO, 2001, art. 8).

Ao longo de todo o documento, o princípio da contribuição para o indivíduo é a origem da defesa da implantação de sistemas de TVET em todas as nações do mundo. Assim, o tamanho do conjunto de contribuições apresentadas indica um pilar fundamental do entendimento acerca da TVET no mundo contemporâneo. 


\subsection{Princípio da contribuição da TVET para o desenvolvimento social}

Na maior parte do documento, o segundo princípio é apresentado como consequência direta do desenvolvimento individual para o progresso social das nações. Nesse sentido, o texto defende que os sistemas de TVET devem estar direcionados para a melhoria da qualidade de vida por meio de uma cultura de aprendizagem que permita aos indivíduos expandirem seus horizontes intelectuais, adquirindo habilidades profissionais que Ihes permitam se envolver positivamente na sociedade (UNESCO, 2001, art. 6b).

Assim, entende-se que os investimentos em criação e manutenção de sistemas TVET pressupõem retornos significativos, entre os quais se inclui o bem-estar dos trabalhadores, a produtividade e a competivividade internacional. De modo que o governo deve prover incentivos financeiros adequados e, nos países menos desenvolvidos, procurar a cooperação para a capacitação bilateral e multilateral (UNESCO, 2001, art. 9c). Destaca-se também que o documento apresenta a defesa do uso da TVET para a maior democratização (UNESCO, 2001, art. 5a).

Ainda em relação a esse princípio, outro ponto pode ser sinalizado na interpretação do texto. Trata-se da compreensão de que a TVET pode ajudar a desenvolver programas de preparação de pessoas em serviços sociais, em uma perspectiva de atendimento comunitário ou familiar, como "enfermagem e profissões paramédicas, nutrição e tecnologia de alimentos, economia doméstica e melhoria do meio ambiente" (UNESCO, 2001, art. 44, tradução nossa).

\subsection{Princípio da TVET como parte integrante da educação básica}

Nas questões expostas pelo documento anteriormente apresentado, o texto eleva a questão da integração à educação básica à condição de um princípio fundamental da TVET. Segundo o texto, essa integração deve se dar com a abolição às barreiras entre níveis e áreas da educação, entre esta e o mundo do trabalho e entre a escola e a sociedade (UNESCO, 2001, art. $6^{\circ}$ ).

Também no sentido da integração à educação básica, o artigo $7^{\circ}$ ainda afirma que os sistemas de TVET devem ser elaborados como parte integral da educação básica de todo indivíduo, como forma de iniciação à tecnologia, ao mundo do trabalho e aos valores humanos da responsabilidade cidadã (UNESCO, 2001, art. $7^{\circ}$ ).

A questão da relação com a educação básica permanece no capítulo IV do documento, intitulado, "Aspectos técnicos e profissionais da educação em geral". Nele, encontra-se a descrição das três funções da TVET na educação básica: a primeira pensada no sentido de um enriquecimento dos processos de ensino-aprendizagem por meio da introdução no mundo do trabalho e da tecnologia, a segunda por meio de uma ação de orientação profissional que favoreça a tomada de decisão de jovens em relação às suas atividades laborais, e a terceira a partir de uma ação de formação que permita o acesso ao trabalho e à carreira por parte dos jovens educandos. 


\title{
3.4 Princípio do aprendizado ao longo da vida
}

O último princípio aparece de forma gradual em vários pontos do texto, porém, é mais bem identificado no capítulo VI, intitulado "Educação Técnica e Profissionalizante como Educação Continuada". Trata-se da defesa da construção de sistemas educacionais que possibilitem a contínua formação de todos os cidadãos de uma nação, em processo constante de atualização, até mesmo, considerando o atendimento de pessoas com idades avançadas. O documento diz que a educação ao longo da vida deve ser criada por meio de

\begin{abstract}
estruturas abertas, flexíveis e complementares de educação, formação e orientação escolar profissional, considerando as disposições da moderna tecnologia da informação na educação, independentemente de essas atividades ocorrerem dentro do sistema de educação formal ou fora dela (UNESCO, 2001, art. 13, tradução nossa).
\end{abstract}

De forma mais precisa, o documento demonstra como o princípio do aprendizado ao longo da vida deve ser entendido na TVET no artigo 46. A educação continuada deve ofertar possibilidades flexíveis de educação a todos, possibilitando a permanente atualização profissional e a adaptação às novas tecnologias. Dito isto, passa-se agora a tratar das normas da TVET identificadas no documento analisado.

\subsection{Norma n. 1: Acesso e Democratização}

A definição geral orientadora, a saber, "padrões de comportamento definidos em termos de direitos e obrigações" (KRASNER, 1983, p. 42) remete também a um cenário ligado ao direito internacional. Boa parte das normas é derivada dos direitos humanos, mais precisamente, do Direito à Educação e do Direito do Trabalho, e também ligada a convenções, como é o caso da norma do Acesso e Democratização, que pode ser remetida à Convenção contra a Discriminação na Educação (UNESCO, 1960).

Durante o trabalho de identificação das normas, prevaleceu a ideia de padrões de comportamento. Foi possível então identificar diversos artigos que buscavam orientar as ações práticas dos sistemas de TVET, em alguns casos, com substancial conteúdo e detalhamento.

Nota-se a busca pela definição de um padrão de atendimento educacional amplo, colocando, inicialmente, no $7^{\circ}$ capítulo, a questão da equidade de gênero no mesmo patamar de importância do atendimento de diversas minorias. Nos artigos 27, 28 e 29, novamente, a questão do acesso igual por homens e mulheres divide espaço com a recomendação de atendimento às minorias, porém, pela primeira vez, apresentam-se no documento os deficientes como público de especial interesse.

0 artigo 52, no capítulo dedicado ao tema da Educação Continuada, também se remete à norma do Acesso e Democratização da TVET, ao propor que deve ter enfoque nos grupos especiais: mulheres que precisam retornar ao mercado de trabalho 
É possível

reconhecer o amplo conjunto de públicos que devem ser atendidos pela TVET após a licença-maternidade; trabalhadores mais velhos e desempregados que precisam se adaptar às novas ocupações; estrangeiros, migrantes, refugiados, indígenas e pessoas com deficiência que precisam se adaptar a uma nova vida ativa; e grupos marginalizados, como jovens fora da escola e desmobilizados em situação de pós-conflito (UNESCO, 2001, art. 52). Assim, é possível reconhecer o amplo conjunto de públicos que devem ser atendidos pela TVET.

\subsection{Norma n. 2: Planejamento e Avaliação}

A norma identificada se concentra em boa parte no capítulo III, com o título "Políticas, planejamento e administração". Segundo o conteúdo do capítulo, as políticas em TVET devem ser formuladas com base no princípio do desenvolvimento social. E para tanto, o documento defende uma visão de TVET como de alta prioridade. Assim, essa norma busca consolidar um padrão de comportamento internacional que toma a TVET como um dos principais assuntos das agendas de desenvolvimento. Nesse sentido, o artigo 10 apresenta algumas das orientações práticas que devem ser atendidas pelas nações:

(a) dar alta prioridade ao ensino técnico e profissional nas agendas nacionais de desenvolvimento, bem como nos planos de reforma educacional;

(b) avaliar as necessidades nacionais de curto e longo prazos;

(c) prestação de atribuições atuais e futuras adequadas de recursos financeiros;

(d) criação de um organismo nacional responsável pela coordenação de planejamento no ensino técnico e profissional com base na análise de dados estatísticos e projeções para facilitar a complementaridade entre política de emprego, planejamento e política educacional (UNESCO, 2001, art. 10, tradução nossa).

Nesse ponto, percebe-se a temática desenvolvimentista da TVET, que se atrela à recomendação de criação de organismos nacionais responsáveis pela elaboração de análises e pesquisas que possam contribuir para a construção de políticas. Estabelece-se, assim, um corpo burocrático capaz de produzir dados e conhecimentos acerca da TVET, considerados fundamentais para o bom investimento com vistas ao desenvolvimento.

Essa norma abrange, ainda, a recomendação de criação de padrões para a TVET pelos órgãos nacionais responsáveis. É disso que trata o artigo 15: a fim de garantir a qualidade, as autoridades nacionais responsáveis devem estabelecer critérios e padrões, sujeitos à revisão periódica e avaliação, aplicando-se a todos os aspectos do ensino técnico e profissional (UNESCO, 2001, art. 15).

Segundo o texto, a padronização e criação de critérios devem ser amplas em seus temas, tratando desde os pré-requisitos de qualificações dos docentes até as insta- 
lações físicas de uma forma geral, passando, até mesmo, pela análise da qualidade dos currículos e materiais didáticos.

Inclui-se nessa norma também a defesa da elaboração de pesquisas de avaliação dos sistemas de TVET. A partir dos padrões e critérios que devem ser estipulados, as avaliações devem favorecer o processo de aumento da qualidade dos programas e cursos de TVET. As avaliações devem ser realizadas em dois sentidos distintos: de um lado, pesquisas que têm como objeto a aprendizagem dos alunos ou questões de ordem pedagógica. De outro lado, as que medem a relação da TVET com o mundo do trabalho de uma forma geral, por meio da análise de indíces e estatísticas socioeconômicas. Nesse último sentido, destaca-se que as estatísticas consideradas relevantes incluem as que se referem às matrículas de tempo parcial, taxas de colocação e abandono, salário e autoemprego (UNESCO, 2001, art. 16d).

Dessa maneira, é possível perceber que o documento defende uma visão de amplo planejamento e avaliação dos sistemas TVET, entendendo-a como política de prioridade em um contexto internacional, baseando-se no princípio do desenvolvimento social.

\subsection{Norma n. 3: Flexibilidade}

A norma da flexibilidade permeia diversos momentos do texto. No entanto, fica mais explícita na parte "Organização", do quinto capítulo, o artigo 31 traz uma ampla orientação acerca dos padrões de organização da TVET, abrangendo as formas tempo integral, meio-turno e aberto a distância.

Segundo esse artigo, a TVET na forma tempo integral deve incluir a educação geral. No meio-turno são sugeridas três formas distintas: dia de lançamento, sistema sanduíche e sistema de lançamento em bloco. A forma aberta a distância abrange os usos de correspondências, TV, rádio e internet.

Por meio de todas essas distintas possibilidades de oferta de TVET, que sugerem até a adoção de postura ativa por parte dos empregadores, o documento defende a construção de um padrão de comportamento dos sistemas de TVET baseado na ideia de diversificação dos meios e formas, tendo em vista o atendimento de todas as realidades inerentes às nações. A educação a distância, entendida como tecnologia fundamental para a democratização do acesso à TVET, é estimulada a partir da recomendação de compras de equipamentos e formação de centros de ensino.

\subsection{Norma n. 4: Trabalho Docente}

O capítulo IX, dedicado ao tema da equipe profissional de TVET, apresenta, inicialmente, a norma relativa ao trabalho docente em seu artigo 74, em que se defende a equiparação do status do docente de TVET em relação aos docentes da educação básica. Em relação aos docentes de TVET: 
A Recomendação relativa ao Estatuto dos Professores adotada pela Conferência Especial Intergovernamental sobre o Estatuto dos Professores em 05 de outubro de 1966 aplica-se a eles, especialmente no que respeita às disposições relativas à preparação para uma profissão, a educação continuada, emprego e carreira, os direitos e as responsabilidades dos professores, as condições para um ensino eficaz e de aprendizagem, os salários dos professores, e da segurança social (UNESCO, 2001, artigo $74 a$, tradução nossa).

Além de questões de direitos dos docentes, a norma presente no texto trata dos padrões de qualificações que abrangem desde a experiência profissional nas ocupações relacionadas aos cursos e programas em que lecionam, bem como conhecimentos específicos da docência em TVET. De uma forma geral, espera-se que a formação dos docentes dos Sistemas de TVET seja ampla, evitando a excessiva especialização, e com foco em questões pedagógicas.

Assim, como pode ser percebido na leitura do artigo 84, a formação de professores da TVET deve ter: a) teorias da educação em geral, técnica e profissional; b) psicologia e sociologia relevantes para a disciplina a ser ministrada; c) gestão da sala de aula, com métodos de ensino e avaliação dos alunos; d) técnicas de ensino utilizando tecnologias da informação e comunicação; e) criação e produção de materiais didáticos modulares e assistidos por computador; f) prática de ensino supervisionado anterior ao cargo; g) orientação escolar e profissional, bem como administração da educação; h) planejamento, gerenciamento e

Espera-se que a formação dos docentes dos Sistemas de TVET seja ampla manutenção das instalações escolares; i) formação em segurança, com ênfase no trabalho seguro (UNESCO, 2001, art. 84 ).

Percebe-se a centralidade que se dá ao trabalho docente, peça fundamental em todos os sistemas TVET, que deve contar com ampla formação continuada, incluindo práticas de intercâmbio profissional com empresas em geral.

\subsection{Norma n. 5: Cooperação Internacional}

No último capítulo do documento, intitulado "Cooperação Internacional", encontram-se os elementos que configuram a norma que busca orientar as práticas cooperativas das nações em TVET. Segundo o texto, os estados-membros devem encorajar a criação de um clima favorável para a cooperação internacional, por meio de parcerias e programas de intercâmbio de professores.

O artigo 99 estimula os países a trocarem experiências em torno de boas práticas que permitam criar padrões internacionais e normas relativas a: sistemas de avaliação; símbolos científicos e técnicos; qualificação e certificação de profissionais; equipamentos e normas técnicas; processamento de informações; equivalências de habilitações que impliquem a padronização dos currículos e testes, incluindo 
testes de aptidão; segurança até no trabalho, por meio de testes de materiais, produtos e processos; proteção e conservação do ambiente (UNESCO, 2001, art. 99).

Percebe-se a defesa de um cenário de cooperação intensa entre as nações acerca da TVET, apontando para um sentido de padronização que deve ser continuamente avaliado e comparado. Finalmente, o último artigo sintetiza o propósito da norma da cooperação internacional, que seria a pesquisa contínua sobre sua aplicação, para que os países usem a educação técnica e profissional ao longo da vida como meio de diminuir as disparidades entre o Norte e o Sul do globo, para que o século 21 seja mais próspero e pacífico (UNESCO, 2001, art. 100).

\section{Considerações finais}

Partindo da fundamentação do conceito de regime internacional nos debates das relações internacionais, e após identificar a ampla variedade de princípios e normas da TVET contidos no documento Revised Recommendation concerning Technical and Vocational Education, foi possível caracterizar a temática da TVET no cenário internacional como assunto de grande importância na agenda de debates acerca do desenvolvimento socioeconômico das nações.

A análise do documento permite compreender que esta modalidade de educação é percebida como um poderoso instrumento de desenvolvimento individual e social, e que, portanto, deve ser compreendida como parte integrante da educação básica, no sentido de garantir o acesso à formação para o trabalho, mas não deve se limitar aos níveis básicos dos sistemas educacionais.

A TVET, da forma como demonstra o documento, deve ser pensada de forma flexível, presente em todos os níveis de ensino e capaz de possibilitar os mais diversos tipos de cursos e programas para o atendimento a um público amplo.

\section{Notas}

'Divididos em 10 capítulos: I. Scope [Escopo]; II. Technical and vocational education in relation to the educational process: objectives [Educação técnica e professional em reção ao processo educacional]; III. Policy, planning and administration [Política, planejmento e administração]; IV. Technical and vocational aspects of general education [Aspesctos técnicos e profissionalizantes da educação em geral]; V. Technical and vocational education as preparation for an occupational field [Educação técnica e profissional como preparação para um ramo ocupacional]; VI. Technical and vocational education as continuing education [Educação Técnica e professional como educação continuada]; VII. Guidance [Orientações]; VIII. The learning processs [0 processo de aprendizado]; IX. Staff [Equipe]; X. International cooperation [Cooperação internacional]. 


\section{Referências}

AMARAL, Marcelo Parreira do. Política pública educacional e sua dimensão internacional: abordagens teóricas. Educação e Pesquisa, São Paulo, v. 36, p. 3954, 2010.

BARDIN, L. Análise de conteúdo. Lisboa: Edições 70: LDA, 2009.

INTERNATIONAL CONGRESS ON TECHNICAL AND VOCATIONAL EDUCATION, 2, 1999. Final report. Paris: Unesco, 1999.

KEOHANE, Robert O. The demand for international regimes. In: KRASNER, Stephen D. (ed.). International regimes. Ithaca: Cornell University Press, 1983.

KRASNER, Stephen D. (ed.). International regimes. Ithaca: Cornell University Press, 1983.

PUCHALA, Donald; HOPKINS, Raymond. International regimes: lessons from inductive analysis. In: KRASNER, Stephen D. (ed.). International regimes. Ithaca: Cornell University Press, 1983.

STRANGE, Susan. Cave! Hic dragones: a critique of regime analysis. International Organization, v. 36, n. 2, p. 479-496, 1982.

UNESCO. Challenges to technical and vocational education: the changing demands of the twenty-first century. [Paris: Unesco, 1999]. Disponível em: http:// www.unesco.org/education/educprog/tve/nseoul/docse/challe.html. Acesso em: 12 mar. 2019.

UNESCO. Convention against Discrimination in Education: adopted by the General Conference at its eleventh session. Paris: Unesco, 1960. Disponivel em: http:// www.unesco.org/education/pdf/DISCRI_E.PDF. Acesso em: 12 mar. 2019.

UNESCO. Convention on Technical and Vocational Education. Paris: Unesco, 1989.

UNESCO. Revised recommendation concerning technical and vocational education. Paris: Unesco, 2001.

YOUNG, Oran. Regime dynamics: the rise and fall of international regimes. In: KRASNER, Stephen D. (ed.). International regimes. Ithaca: Cornell University Press, 1983. 